\title{
Green Tea Extract Exerts Anabolic Effects on Extracellular Matrix of the Skin
}

\author{
M. TURKOGLU, E. PEKMEZCI ${ }^{1 *}$ AND S. KILIC \\ Biota Laboratories, R \& D Center, Istanbul, 34785, ${ }^{1}$ Istanbul Medipol University, Department of Dermatology, Istanbul, \\ 34214, Turkey
}

Turkoglu et al: : Anabolic Effects of Green Tea Extract on Skin

\begin{abstract}
An in vitro trial was carried out to reveal the effects of an extract of Camellia sinensis (green tea extract) on the major extracellular matrix components of human skin. After preparing the green tea extract its phytochemical contents were analysed and its effects on gene expression of hyaluronan synthase 2, matrix metalloproteinase-9 and elastase in a human dermal fibroblast cell line were determined. Cell proliferation assay was performed using XTT reagent. Ribonucleic acid isolations were realized by using TRI reagent. Expressions of the relevant enzymes and a control enzyme glyceraldehyde-3-phosphate dehydrogenase were determined using RT-qPCR analysis. Green tea extract caused statistically significant upregulation of hyaluronan synthase-2 gene expression compared to untreated control cells. Also, as a positive outcome, the treatment resulted in significant downregulations of matrix metalloproteinase-9 and elastase gene expressions. Green tea extract was found to have substantial anabolic effects on hyaluronic acid, collagen and elastin. The results obtained in this study might partially explain the molecular basis of the health benefits and antiaging effects of Camellia sinensis on skin.
\end{abstract}

Key words: Camellia sinensis, green tea, hyaluronan synthase, matrix metalloproteinase, elastase

Tea plant, Camellia sinensis, is a member of the Theaceae family. Polyphenolic compounds called cathecins are thought to be responsible for the majority of health benefits associated with this plant. The potential health benefits of $C$. sinensis on skin include, protection from the detrimental effects of ionizing and ultraviolet (UV) radiation, improvement in wound healing and cancer chemoprevention ${ }^{[1-3]}$. Author's previous studies reported that black or green tea extracts protected the skin from a direct UV exposure preventing sunburn and erythema ${ }^{[4,5]}$. Tea polyphenols alleviate the UVB-induced destructive morphological changes in human keratinocyte (HaCaT) cell line via interacting with induced reactive oxygen species $(\mathrm{ROS})^{[2]}$. Sunscreens containing 2-3 \% C. sinensis extract substantially protect against photoaging and photoimmunology related biological events such as cutaneous erythema and epidermal 
thickening ${ }^{[6]}$. Cream with $10 \%$ C. sinensis extract and $300 \mathrm{mg}$ twice daily green tea oral supplementation, which were given to moderately photoaged women revealed significant improvement in the elastic tissue contents of analysed specimens ${ }^{[7]}$. Topical application of various $C$. sinensis extracts found effective in atopic dermatitis, acne vulgaris and rosacea ${ }^{[8]}$. In an animal study, topical application of $20 \%$ C. sinensis extract significantly increased fibroblast growth, collagen synthesis and thus the healing process by increasing the rate of wound healing ${ }^{[1]}$. Tea polyphenols lead to retardation in initiation of tumorigenesis, reduction in cumulative number of tumor cells and increased tumor-free survival in experimentally-induced skin carcinogenesis in mice ${ }^{[9]}$. Oral administration of green tea polyphenols in drinking water or the topical application of epigallocathecin-3-gallate (EGCG), the major catechin in C. sinensis, prevent UVB-induced skin tumor development in mice ${ }^{[10]}$. In a retrospective study on patients who had cancer of the head, neck or pelvic region receiving radiotherapy, topically administered C. sinensis extracts supported the reparation of skin integrity, inhibited proteasome function and suppressed cytokine release $^{[11]}$.

Hyaluronic acid (HA), collagen and elastin bind each other and make up a three dimensional structure, which is impaired in aged or damaged skin due to internal or external causes ${ }^{[12]}$. With regard to the numerous reports about $C$. sinensis on the well being of skin, in this study it was aimed to reveal the probable direct causes of cutaneous health and also the effects of this plant on the major structural components of the human integumentary system. The effects of $C$. sinensis on the gene expression of three enzymes, hyaluronan synthase-2 (HAS-2), matrix metalloproteinase-9 (MMP-9) and elastase, which are crucial in the metabolism of HA, collagen and elastin, respectively, are studied in a human dermal fibroblast cell line.

\section{MATERIALS AND METHODS}

The leaves of $C$. sinensis were purchased from Martin Bauer Group. Dried leaves (12.5 g) were extracted with $500 \mathrm{ml}$ distilled water by boiling for $15 \mathrm{~min}$. The extract was filtered through a $0.45 \mu \mathrm{m}$ filter paper. Content of catechins in green tea was analysed according to a HPLC method $^{[13]}$ suitably modified as the following, HPLC on

*Address for correspondence

E-mail: erkinpekmezci@gmail.com

369
Luna ${ }^{\circledR}$ Phenyl-Hexyl column with a solvent gradient of $2 \%$ acetic acid-acetonitrile with EDTA; acetonitrile $9-32 \%$ over $15 \mathrm{~min}$ at $278 \mathrm{~nm}$ and temperature was kept at $35^{\circ}$.

A solution of 2,2-diphenyl-1-picrylhydrazyl (DPPH, $0.1 \mathrm{mM}$ ) in methanol was prepared and $1 \mathrm{ml}$ of this solution was added to $1 \mathrm{ml}$ of all extracts in methanol at different concentrations $(50,100,200,400$, $800 \mu \mathrm{g} / \mathrm{ml}$ ). The mixtures were allowed to stand at room temperature for $30 \mathrm{~min}$. The absorbance was measured at $517 \mathrm{~nm}$ using a UV/Vis spectrophotometer. Ascorbic acid was used as the reference standard. The capability of scavenging DPPH radical was calculated using the following formula, DPPH scavenging effect $(\%$ inhibition $)=(\mathrm{A} 0-\mathrm{A} 1) / \mathrm{A} 0) \times 100$, where, $\mathrm{A} 0$ is the absorbance of the control reaction and $\mathrm{A} 1$ is the absorbance in presence of all extract samples or reference standard. All tests were performed in triplicate and the results were averaged.

The total phenolic content of the extract was estimated using Folin-Ciocalteu reagent. Ten milligrams of gallic acid, the standard, was dissolved in $100 \mathrm{ml}$ distilled water. One millilitre of the extract and standard gallic acid at different concentrations $(10,20,40,60,80$, $100 \mu \mathrm{g} / \mathrm{ml}$ ) were mixed with $5 \mathrm{ml}$ of distilled water and $0.5 \mathrm{ml}$ of Folin-Ciocalteu reagent. After $5 \mathrm{~min}, 1.5 \mathrm{ml}$ of $20 \%$ sodium carbonate was added and volume was adjusted to $10 \mathrm{ml}$ with distilled water and incubated for $2 \mathrm{~h}$ at room temperature. Absorbance was measured at $750 \mathrm{~nm}$. A calibration curve was plotted using standard gallic acid. Total phenolic content of the extract was expressed as mg of gallic acid equivalents. All the tests were performed in triplicate and the results were averaged.

Total flavonoid content was evaluated using the aluminium chloride colorimetric assay. Four millilitres of distilled water and $0.3 \mathrm{ml}$ of $5 \%$ sodium nitrite solution were added to $1 \mathrm{M}$ of extract and $1 \mathrm{ml}$ of standard quercetin solution at different concentrations $(100,200,400,600,800,1000 \mu \mathrm{g} / \mathrm{ml})$. Aluminum chloride solution $(10 \%, 0.3 \mathrm{ml})$ was added to each tube.

This is an open access article distributed under the terms of the Creative Commons Attribution-NonCommercial-ShareAlike 3.0 License, which allows others to remix, tweak, and build upon the work non-commercially, as long as the author is credited and the new creations are licensed under the identical terms

Accepted 17 January 2020

Revised 20 December 2019

Received 05 August 2019

Indian J Pharm Sci 2020;82(2):368-373 
After $5 \mathrm{~min}, 2 \mathrm{ml}$ of $1 \mathrm{~m}$ sodium hydroxide was added. Finally, volume was made up to $10 \mathrm{ml}$ with distilled water. The absorbance was measured at $510 \mathrm{~nm}$. A calibration curve was plotted using standard quercetin. The total flavonoids of the extract were expressed as mg of quercetin equivalents. All the tests were performed in triplicates and the results were averaged.

Fibroblast cells were cultured in DMEM with high glucose, supplemented with $15 \%$ heat-inactivated fetal bovine serum and $1 \%$ gentamicin. The cells were maintained at $37^{\circ}$ in a humidified atmosphere of $5 \%$ $\mathrm{CO}_{2}$ in a Newbrunswick incubator. All supplements and media were purchased from Sigma Aldrich. The cellular toxicity of green tea extract was investigated with XTT cell proliferation assay. The cells were seeded into 96 -well plates $\left(1 \times 10^{4}\right.$ cells/well $)$ and were incubated $24 \mathrm{~h}$ at $37^{\circ}$, in a humidified atmosphere of $5 \% \mathrm{CO}_{2}$. New medium was added on every 2 nd day after aspirating the previous medium, treated with different concentrations $(10,5,3,1,0.1$ and $0 \%)$ of green tea extract and incubated under the same conditions for $72 \mathrm{~h}$. XTT reagent was added to the plates after the incubation period to obtain a concentration of $0.3 \mathrm{mg} / \mathrm{ml}$ according to the manufacturer's (Roche Diagnostics) instructions. Then, cells were incubated at $37^{\circ}$ for $4 \mathrm{~h}$ to get the XTT reagent reduced to orange formazan compound. The optical density of soluble formazan compound was measured at $450 \mathrm{~nm}$ with $650 \mathrm{~nm}$ reference in a microplate reader (Bio-Rad). Based on cell proliferation ratios of treated cells with respect to the control cells, cytotoxicity levels of the green tea extract were determined. Higher concentrations of the extract were found to be cytotoxic for fibroblast cells. In these studies principally the concentration of the extract chosen was the one which gave nearest to $80 \%$ cell proliferation ratio. Generally to have this ratio higher, a very low concentration is necessary, which may be inappropriate for the experiment. Therefore, the possible highest concentration was determined as $0.1 \%$ and fibroblast cells were incubated with $0.1 \%$ concentration of extract solution before total RNA isolation (fig. 1). Total RNA was extracted from cells treated with green tea extract and from untreated cells using TRI reagent according to manufacturer's (Sigma Aldrich) instructions. The concentration and purity of isolated RNA samples were determined by measuring optical densities at $260 \mathrm{~nm}$ and $280 \mathrm{~nm}$ using a BioSpecnano. Transcriptor First Strand cDNA Synthesis Kit (Roche Diagnostics) was used for cDNA synthesis. Five hundred nanograms of total RNA and $10 \mathrm{mM}$ gene specific primers of HAS-2, MMP-9 and elastase as study material and glyceraldehyde-3-phosphate dehydrogenase (GAPDH) as control (Integrated DNA Technologies) were added in RNAse free test tubes and the final volume was made up to $13 \mu \mathrm{l}$ for each by adding distilled water. After incubation for $10 \mathrm{~min}$ at $65^{\circ}$ in a Thermal Cycler, the tubes were placed over ice. Later they were incubated for $30 \mathrm{~min}$ at $55^{\circ}$ and $5 \mathrm{~min}$ at $85^{\circ}$ in the Thermal Cycler, after adding $4 \mu 1$ of reverse transcription buffer (5X), $2 \mu 1$ of dNTP mix $(10 \mathrm{mM}), 0.5 \mu 1$ of protector RNAse inhibitor and 0.5 $\mu 1$ of reverse transcriptase. Primer sequences are given in Table 1.

Fast Start DNA Green Master Kit (Roche Diagnostics) was used for the real-time quantitative polymerase chain reactions (RT-qPCR). Briefly, total volume of reaction mix was $20 \mu 1$, containing $10 \mu 1$ Master Mix, $10 \mathrm{mM}$ each of reverse and forward primers, $25 \mathrm{ng}$ template cDNA and appropriate amount of RNAse free distilled water. All samples were run as triplicates in each run including a non-template control and 4 standards $(1: 1,1: 10,1: 100,1: 1000)$. The RT-qPCR parameters were determined separately for each target according to melting and annealing temperatures of primers. Each parameter included a pre-incubation step for $10 \mathrm{~min}$ at $95^{\circ}$ and followed by 45 cycles of 3 amplification and melting steps. Melting curve analysis was performed to verify specificity. Absolute quantification analysis was performed by using Light Cycler 96 (Roche Diagnostics). For quantitation of RT-qPCR results, $\Delta \Delta \mathrm{C}_{\mathrm{t}}$ method was used. The gene expression results were represented as Target/GAPDH fold change. All data were representative of three experiments and expressed as mean \pm standard deviation. Statistical evaluation was performed by non-parametric Mann-Whitney test (GraphPad Prism 6) and statistical significance was defined as $\mathrm{p}<0.05$.

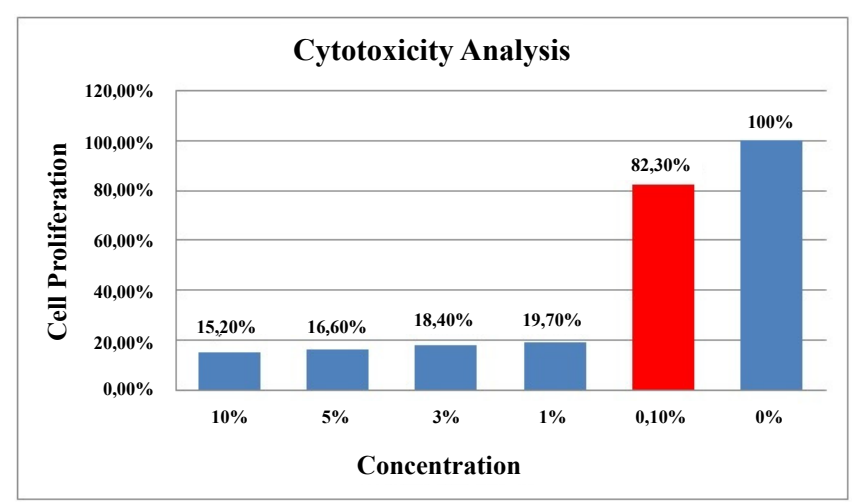

Fig. 1: Cell proliferation ratios

Cell proliferation ratios at decreasing concentrations of the green tea extract. Red bar represents the concentration chosen for incubation 
TABLE 1: PRIMERS (5'-3') OF THE GENES STUDIED

\begin{tabular}{lcc}
\hline Primers & Forward primer & Reverse primer \\
\hline HAS-2 & GCCTGGGCTATGCAACAAAA & GTAGGACTTGCTCCAACGGG \\
MMP-9 & GTACTCGACCTGTACCG & AGAAGCCCCACTTCTTGTCG \\
Elastase & CTGGCCTCGGAGATTGTGG & GGACGTTTACATTCGCCACG \\
GAPDH & ATGGGTGTGAACCATGAGAA & GTGCTAAGCAGTTGGTGGTG \\
\hline
\end{tabular}

TABLE 2: THE QUANTITIES OF CATECHINS IN GREEN TEA

\begin{tabular}{|c|c|c|c|c|c|c|c|c|c|}
\hline Catechins* & $\overline{G A}$ & GC & EGC & $\mathrm{C}$ & CAF & EC & EGCG & GCG & ECG \\
\hline $\mathrm{g} / 100 \mathrm{~g} \mathrm{dm}^{\S}$ & 0.011 & 0.284 & 3.477 & 0.068 & 2.567 & 0.670 & 7.965 & 0.193 & 1.386 \\
\hline
\end{tabular}

TABLE 3: ANTIOXIDANT ACTIVITY, PHENOLIC AND FLAVONOID CONTENT OF THE GREEN TEA EXTRACT

\begin{tabular}{lcc}
\hline Antioxidant activity & Phenolic content & Flavonoid content \\
\hline $96.27 \%$ (10\% ascorbic acid equivalent) & $9.74 \mathrm{mg} / \mathrm{ml}$ (gallic acid equivalent) & $0.19 \mathrm{mg} / \mathrm{ml}$ (quercetin equivalent) \\
\hline
\end{tabular}

\section{RESULTS AND DISCUSSION}

The quantities of catechins obtained by HPLC analysis of green tea are shown in Table 2. The total antioxidant activity, phenolic and flavonoid contents of the green tea extract are depicted in Table 3. Green tea extract caused statistically significant upregulation of HAS-2 gene expression $(\mathrm{p}<0.05)$ compared to untreated control cells. Also, as a positive outcome, the treatment revealed significant downregulations of MMP-9 and elastase $(\mathrm{p}<0.05)$ gene expressions. The treatment ended up with $1.518 \pm 0.125,0.353 \pm 0.178$, and $0.240 \pm 0.096$ fold changes for HAS-2, MMP-9, and elastase, respectively. The fold changes of the gene expression analyses are depicted in fig. 2 .

HA, a large unsulfated glycosaminoglycan, is expressed by various cell types and possesses functional roles in cellular adhesion, proliferation, migration, and differentiation $^{[14]}$. In mammals there are 3 forms of HAS that have different properties. HAS-1 and HAS2 give rise to high molecular weight HAs, but HAS3 is involved in the generation of a lower molecular weight variant. HAS-1 is by far the least active of these enzymes, while HAS-2 and HAS-3 show approximate degrees of activity ${ }^{[15]}$. The concentrations of HAs in various tissues are in correlation with the transcription of HAS genes, especially with HAS-2 $2^{[16]}$. HA is a substantial component of the dermis, which is responsible for conjugating water and keeping dermal volume $^{[12]}$. It was reported that HAS-2 protects skin fibroblasts against apoptosis induced by environmental stress, mainly $\mathrm{UVB}^{[17]}$. In senile fibroblasts, HAS2-mediated HA synthesis decreases significantly ${ }^{[18]}$. It is also demonstrated the physiological role of HA in epidermal keratinocytes. The migration rate of

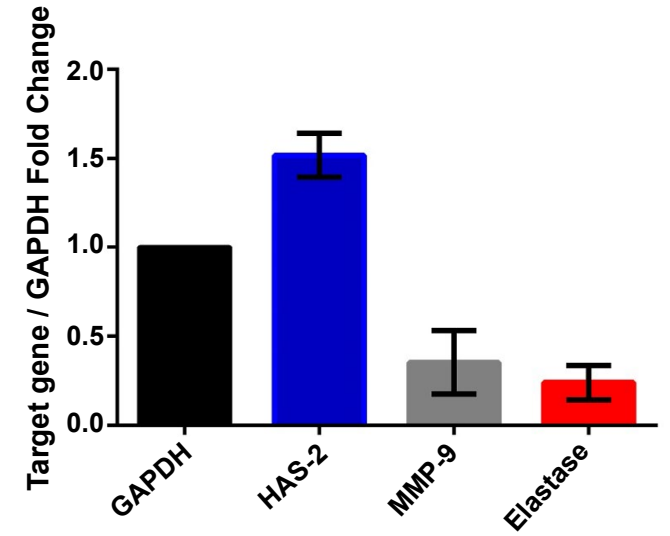

Fig. 2: Gene expression levels of HAS-2, MMP-9 and elastase

Gene expression levels of HAS-2, MMP-9 and elastase after the treatment with green tea extract, compared to untreated control cells

keratinocytes in scratch wounded monolayer cultures is regulated by HAS-2-induced HA synthesis ${ }^{[16]}$. Enhanced HA synthesis by increased HAS-2 and HAS3 expressions is an aspect of the keratinocyte activation due to tissue trauma and important for a perfect healing course ${ }^{[19]}$. The synthesis of HA regulated by HAS-2, causes keratinocyte migration, which is crucial for the reconstruction of squamous epithelia after wounding ${ }^{[20]}$. MMPs are zinc containing peptidases and these interfere with the various components of extracellular matrix (ECM). They are secreted by keratinocytes and dermal fibroblasts in reaction to numerous stimuli such as oxidative stres, UV and cytokines. More than 20 different types of MMPs have been identified that play important roles in various pathophysiological processes including photoaging, wound healing, angiogenesis and cancer development ${ }^{[21]}$. In many inflammationassociated diseases, such as chronic wounds and cancers, 
these proteinases are predominantly expressed. They activate quiescent cells, stimulate cell migration and initiate cell differentiation ${ }^{[22]}$. The main characteristic changes during remodeling of the dermal ECM due to UVB irradiation are, upregulation of MMPs and subsequent cleavage of collagen, fibronectin, elastin and proteoglycans, contributing to photoaging ${ }^{[23]}$. MMP-9 is a member of the gelatinase subgroup of MMPs also known as gelatinase B. Gelatinases are associated with cancer invasion in the skin because they mainly degrade collagen type IV, which is an essential component of the basement membrane of the epidermis. MMP-9 can also degrade other substrates such as collagen type V, VII, $X$, fibronectin and elastin ${ }^{[21]}$. MMP-9, is thought to have critical functions in the remodeling of the basement membrane zone because several ECM proteins in this region have been determined as the substrates of this proteinase $^{[22]}$. The greater invasive feature of squamous cell carcinoma (SCC) compared to that of basal cell carcinoma is probably due to the enhanced expression and activity of gelatinases in the former and therefore, among the MMPs, MMP-9 is the most critical one in SCC tumorigenesis ${ }^{[21]}$. MMP-9 is the main proteinase responsible from the aberrant wound healing. Elevated MMP-9 levels have been demonstrated in various chronic wound types. There is a substantial increase of MMP-9 at the chronic wound environment and it was shown that healed areas of burn wounds and leg ulcers lost active MMP-9 expression ${ }^{[24]}$. Also, diabetic patients with chronic, non-healing foot ulcers are found to have higher MMP-9 serum levels compared to those patients who are treatment responsive ${ }^{[25]}$. Elastic fibers, which are among the crucial components of connective tissue, give resilience and elasticiy to the skin. Elastic fibers are cleaved by the elastolytic enzymes, principally human leucocyte elastase (HLE) ${ }^{[12]}$. Although under normal physiologic conditions elastase is a powerful agent for host defence ${ }^{[26]}$, it is involved in tissue destruction in numerous chronic inflammatory diseases ${ }^{[27]}$. HLE is unable to cleave intact elastin but may promote further disruption of elastic fibers secondary to the action of other proteases ${ }^{[28]}$. Wrinkle development in the skin due to long term UVB exposure is associated with impairment of elastic fibers in the dermis. Fibroblast elastase, which is the major elastase in the skin under non-inflammatory conditions, has a particular role in the disruption of elastic fibers due to cumulative UVB exposure ${ }^{[29]}$. Studies have also demonstrated a reduction in the elastin content of the skin, even in the protected areas, due to intrinsic aging ${ }^{[2]}$. Although the long term exposure of skin to UVB primarily evokes wrinkling, UVA predominantly brings out sagging. Increased activity of fibroblast derived elastase in the skin has an important function in wrinkling and sagging as a result of elastic fiber degradation ${ }^{[30]}$. Nevertheless, the insufficiency of sunscreens alone, proposes the idea that the combination of a sunscreen and an elastase inhibitor might be more effective ${ }^{[31]}$.

This study analysed the effects of $C$. sinensis green tea extract, on the gene expressions of 3 enzymes responsible for the metabolism of structural components of healthy skin, through a human dermal fibroblast cell line. In terms of fold change, the increase in HAS-2, and the decreases in both MMP-9 and elastase, which were all positive outcomes, were found significant (fig. 2). Generation of ROS and downturning of cell functions caused by long term exposures to environmental and intrinsic offences, result in tissue damage. These inflammmatory responses enhance the synthesis of dermal enzymes which lead to degradation of $\mathrm{ECM}^{[32]}$. Breakdown and disorganisation of ECM components are the predominant features of skin aging and inhibiton of pathologic enzymatic activities by natural plant compounds might be a promising approach to prevent the above-mentioned degradation ${ }^{[33]}$. In general it may be considered that green tea extract has a substantial anabolic effect on HA, collagen and elastine, which are the 3 major extracellular structural components of the skin. It is quite possible that these results are mainly due to the plant's strong antioxidant activity related to its phenolic and flavonoid constituents supplied by the abundant content of cathecins which are also demonstrated by the phytochemical analyses performed (Tables 2 and 3). Suppression of the degradation of ECM and increasing the relevant 3 major structural components of skin is the well known target of antiaging studies and cosmetic dermatology and it is an established opinion that these 3 components must be increased in order to give skin a younger and healthier appearance ${ }^{[12]}$. Therefore, considering the significant anabolic effects of green tea extract in dermal ECM, it can be suggested that $C$. sinensis has a promising future in cosmetic dermatology. The results obtained in this study might also partially explain the molecular basis of the health benefits of $C$. sinensis on skin, including cancer chemoprevention, improvement in wound healing, and protection against the detrimental effects of UV exposure.

\section{REFERENCES}

1. Hajiaghaalipour F, Kanthimathi MS, Abdulla MA, Sanusi J. 
The effect of Camella sinensis on wound healing potential in an animal model. Evid Based Complement Alternat Med 2013;2013:386734.

2. Wy LY, Zheng XQ, Lu JL, Liang YR. Protective effect of green tea polyphenols against ultraviolet-B induced damage to HaCaT cells. Hum Cell 2009;22(1):18-24.

3. Nagle DG, Ferreira D, Zhou YD. Epigallocathecin-3gallate (EGCG): Chemical and biomedical perspectives. Phytochemistry 2006;67(17):1849-55.

4. Turkoglu M, Cigirgil N. Evaluation of black tea gel and its protection potential against UV. Int $\mathrm{J}$ Cosmet Sci 2007;29(6):437-42.

5. Turkoglu M, Uğurlu T, Gedik G, Yılmaz AM, Yalcin AS. In vivo evaluation of black and green tea dermal products against UV radiation. Drug Discov Ther 2010;4(5):362-7.

6. Li YH, Wu Y, Wei HC, Xu YY, Jia LL, Chen J, et al. Protective effects of green tea extracts on photoaging and photoimmunosuppression. Skin Res Technol 2009;15(3):33845.

7. Chiu AE, Chan JL, Kern DG, Kohler S, Rehmus WE, Kimball AB. Double blinded, placebo-controlled trial of green tea extracts in the clinical and histologic appearance of photoaging skin. Dematol Surg 2005;31(7Pt2):855-60.

8. Pazyar N, Feily A, Kazerouni A. Green tea in dermatology. Skinmed 2012;10(6):352-5.

9. Roy P, Nigam N, George J, Srivastava S, Shukla Y. Induction of apoptosis by tea polyphenols mediated through mitochondrial cell death pathway in mouse skin tumors. Cancer Biol Ther 2009;8(13):1281-7.

10. Katiyar S, Elmets CA, Katiyar SK. Green tea and skin cancer: photoimmunology, angiogenesis and DNA repair. J Nutr Biochem 2007;18(5):287-96.

11. Pajonk F, Riedisser A, Henke M, McBride WH, Fiebich B. The effects of tea extracts on proinflammatory signaling. BMC Med 2006;4:28.

12. Baumann L, Saghari S. Basic science of dermis. In: Baumann L, Saghari S, Weisberg E, editors. Cosmetic Dermatology. 2nd ed. New York: McGraw-Hill; 2009. p. 8-13.

13. ISO Geneva, Switzerland, Determination of substances characteristic of green tea and black tea. Part 2: Content of cathecins in green tea-method using high performance liquid chromatography. ISO 14502-2: 2005.

14. Pasonen-Seppanen S, Karvinen S, Törrönen K, Hytinnen JM, Jokel T, Lammi MJ, et al. EGF upregulates, whereas TGF- $\beta$ downregulates, the hyaluronan synthases Has 2 and Has 3 in organotypic keratinocyte cultures: correlations with epidermal proliferation and differentiation. J Invest Dermatol 2003;120:1038-44.

15. Gebhardt C, Averbeck M, Diedenhofen N, Willenberg A, Anderegg U, Sleeman JP, et al. Dermal hyaluronan is rapidly reduced by topical treatment with glucucorticoids. J Invest Dermatol 2010;130:141-9.

16. Saavalainen K, Pasonen-Seppanen S, Dunlop TW, Tammi R, Tammi MI, Carlberg C. The human hyaluronan synthase 2 gene is a primary retinoic acid and epidermal growth factor responding gene. J Biol Chem 2005;280(15):14636-44.

17. Wang Y, Lauer ME, Anand S, Mack JA, Maytin EV. Hyaluronan synthase 2 protects skin fibroblasts against apoptosis induced by environmental stress. J Biol Chem 2014;289(46):32253-65.

18. Röck K, Tigges J, Sass S, Schütze A, Florea AM, Fender AC, et al. miR-23a-3p causes cellular senescence by targeting hyaluronan synthase 2 : possible implication for skin aging. $\mathrm{J}$ Invest Dermatol 2015;135(2):368-77.
19. Tammi R, Pasonen-Seppanen S, Kolehmainen E, Tammi M. Hyaluronan synthase induction and hyaluronan accumulation in mouse epidermis following skin injury. J Invest Dermatol 2005;124(5):898-905.

20. Rilla K, Lammi MJ, Sironen R, Törrönen K, Luukkonen M, Hascall VC, et al. Changed lamellipodial extension, adhesion plaques and migration in epidermal keratinocytes containing constitutively expressed sense and antisense hyaluronan synthase 2 (Has2) genes. J Cell Sci 2002;115(Pt18):3633-43.

21. Pittayapruek P, Meephansan J, Prapapan O, Komine M, Ohtsuki M. Role of matrix metalloproteinases in photoaging and photocarcinogenesis. Int J Mol Sci 2016;17:868.

22. Han YP, Yan C, Garner WL. Proteolytic activation of matrix metalloproteinase-9 in skin wound healing is inhibited by alpha-1 antichymotrypsin. J Invest Dermatol 2008;128(9):2334-42.

23. Röck K, Grandoch M, Majora M, Krutmann J, Fischer JW. Collagen fragments inhibit hyaluronan synthesis in skin fibroblasts in response to ultraviolet B (UVB): new insights into mechanisms of matrix remodeling. J Biol Chem 2011;286(20):18268-76.

24. Reiss MJ, Han YP, Garcia E, Goldberg M, Yu H, Garner WL. Matrix metalloproteinase-9 delays wound healing in a murine wound model. Surgery 2010;147(2):295-302.

25. Dinh T, Tecilazich F, Kafanas A, Doupis J, Gnardellis C, Leal $\mathrm{E}$, et al. Mechanisms involved in the development and healing of diabetic foot ulceration. Diabetes 2012;61:2937-47.

26. Barros SC, Martins JA, Marcos JC, Cavaco-Paulo A. Influence of secretory leukocyte protease inhibitor-based peptides on elastase activity and their incorporation in hyaluronic acid hydrogels for chronic wound therapy. Biopolimers 2012;98(6):576-90.

27. Lee SK, Lee SS, Song IS, Kim YS, Park YW, Joo JY, et al. Paradoxical effects of elastase inhibitor guamerin on the tissue repair of two different wound models: sealed cutaneous and exposed tongue wounds. Exp Mol Med 2004;36(3):259-67.

28. Schmelzer CE, Jung MC, Wohlrab J, Neubert RH, Heinz A. Does human leukocyte elastase degrade intact skin elastin? FEBS J 2012;279(22):4191-200.

29. Tsukahara K, Takema Y, Moriwaki S, Tsuji N, Suzuki Y, Fujimura $\mathrm{T}$, et al. Selective inhibition of skin fibroblast elastase elicits a concentration-dependent prevention of ultraviolet B-induced wrinkle formation. J Invest Dermatol 2001;117:671-7.

30. Imokawa G, Ishida K. Biological mechanisms underlying the ultraviolet radiation-induced formation of skin wrinkling and sagging I: reduced skin elasticity, highly associated with enhanced dermal elastase activity, triggers wrinkling and sagging. Int J Mol Sci 2015;16:7753-75.

31. Tsukahara K, Moriwaki S, Hotta M, Fujimura T, SugiyamaNagakiri Y, Sugawara S, et al. The effect of sunscreen on skin elastase activity induced by ultraviolet-A irradiation. Biol Pharm Bull 2005;28(12):2302-7.

32. Maity N, Nema NK, Sarkar BK, Mukherjee PK. Standardized Clitoria ternatea leaf extract as hylauronidase, elastase and matrix-metalloproteinase-1 inhibitor. Indian $\mathrm{J}$ Pharmacol 2012;44(5):584-7.

33. Wittenauer J, Mackle S, Susmann D, Schweiggert-Weisz U, Carle R. Inhibitory effects of polyphenols from grape pomace extract on collagenase and elastase activity. Fitoterapia 2015;101:179-87. 